\title{
AXALAPASCO DE. TACÁMBARO.
}

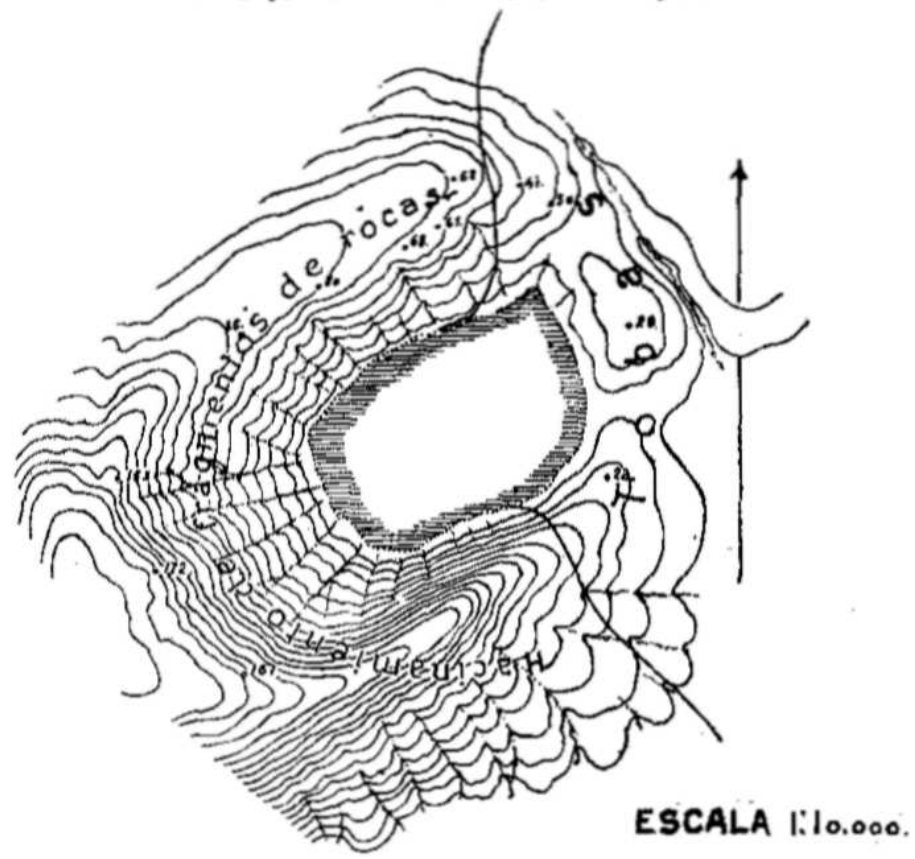


EL AXALAPAZCO DE TACÁMBARO,

por Pascual Ortiz Rubio.

El cráter-lago ó Axalapazco, conocido con el nombre de Alberca de Tacámbaro, se halla situado en la falda del cerro alto de la Corucha, eminencia de cima alargada en forma de cresta de cerca de 2 kilómetros de longitud, que por la forma encorvada y por la naturaleza de las rocas que la constituyen en su totalidad, pensamos que guarda aún el aspecto de un antiguo volcán destruido por la erosión. El Axalapazco de que se trata, situado á 3 kilómetros de la hacienda de Chupio, ubicada en las mismas estribaciones del Cerro de la Corucha, consiste de una cavidad de forma aproximadamente elíptica, con el eje mayor orientado de S. W. á N. E., correspondiendo á esta dirección, la mayor diferencia de altura de los bordes que ha resultado naturalmente de la posición de esta moderna estructura volcánica, en las faldas del grueso macizo de la Corucha. En efecto, el borde S. W. del Axalapazca, que forma parte de ese macizo, aparece como una gran pared casi escarpada, de 172 metros de altura sobre el nivel de las aguas que cubren el fondo de la cavidad, cuyos bordes van descendiendo gradualmente hacia el Sur y 
hacia el Norte, para morir hacia el NE. y E. en un ancho reborde de 15 á 20 metros arriba del nivel de las aguas, único espacio donde las paredes. interiores no muestran las fuertes pendientes que dan á este cráter su aspecto salvaje é imponente, digno de figurar con ventaja entre las demás construcciones mexicanas del mismo origen y naturaleza, que aunque siendo muchas de ellas de mayores dimensiones y altura, no tienen, como la Alberca de Tacámbaro, la cubierta de vegetación tupida de grandes coníferas que cubre las paredes más altas y pendientes, ó sea las partes conservadas de roca maciza preexistente, que asoma en partes con paredes acantiladas; en contraste con la desnudez de los bordes rebajados, construidos con el material de acumulación, fruto de la explosión que dió origen á la cavidad. Las aguas, de un tinte azul verdoso característico, invaden el fondo hasta el pie de los escarpes y cantiles aureolados de una cinta verde de plantas acuáticas. No hay más playas que una angosta media luna al oriente y que tiene fácil acceso por estar inmediata al borde de menor elevación. De los sondeos minuciosos que hemos hecho, resulta que las aguas no cubren más que el fondo de una cavidad embudiforme, cuyas inclinaciones, hasta el punto central, no son sino la continuación de los taludes arriba de las aguas, y dicho punto más profundo, que sólo está á 27 metros de la superficie del líquido, está exéntrico á causa de que las paredes cantiladas continúan del mismo modo en el seno de las aguas.

Las aguas no son muy saladas: esperamos poder dar más tarde un análisis de ellas. Dichas aguas deben de su 
frir una renovación, porque un pez pequeño vive y se propaga.

Acompañamos á esta nota un pequeño plano que puede dar una buena idea del conjunto del hermoso Axalapazco de Tacámbaro. Acotaciones convenientemente distribuidas, pormenorizan las diferencias de nivel.

Las dimensiones del Axalapazco son como sigue:-

Eje mayor de la elipse de borde á borde Eje mayor de la elipse al nivel del agua 800 Eje menor de la elipse de borde á borde 375 Eje menor de la elipse al nivel del agua

Como todos los cráteres de explosión (Xalapazcos), el de Tacámbaro es de muy sencilla constitución, como se habrá podido comprender. Entran formando parte de él, como hemos dicho, la roca pre-existente de la Corucha, que comprende casi las tres cuartas partes de las paredes y bordes del cráter. Esta es una roca dura, de color rojizo de naturaleza basáltica, que se encuentra en Michoacán en gran abundancia, cubriendo en grandes malpaís, áreas inmensas de terreno. La grande cavidad se completa con los productos de la explosión que yacen acumulados en capas muy regulares, á veces con doble inclinación (cuacuaversales) y escalonadas en partes por efecto de la erosión. Dichas capas, poco consistentes y aun de material incoherente, tienen un color gris y gris amarillento, como las tobas de todos los volcanes del tipo de explosión. Estas tobas responden á la composición del basalto. Ade 
más las tobas, que no son más que el resultado de la acumulación de las partículas muy finas y vidriosas, que como polvo son lanzadas por la explosión, se encuentran intercaladas capas delgadas de cenizas gruesas de color gris negruzco y capitas de lopilli que se ven como cintas negras en las paredes interiores.

Las capas contienen fragmentos arredondados de otras rocas, indudablemente arrancados de las paredes de la chimenea, cuyos fragmentos, ya angulosos, ya arredondados, son de rocas andesíticas, de basalto igual al de las paredes occidentales del cráter, fragmentos y bombas de basalto negro que viene del residuo de magma, donde se verificó la explosión, y por último, bolas pedruzcos esquinados de una roca gris, conteniendo gruesos cristales porfiríticos de feldespato, de hornblenda y de biotita, que referimos á una andesita de piroxena y hornblenda, que, á su vez, abunda en las vastas regiones volcánicas de Michoacán y es más antigua que los basaltos de la Corucha.

Es indudable que el Axalapazco de tacámbaro ha soportado los efectos prolongados de una activa erosión que ha suprimido una gran cantidad de material de la explosión acumulado alrededor del orificio. La roca de la Corucha, por su dureza, ha mantenido aún vigorosas las formas primitivas de la cavidad, y que en un tiempo se vieron, en los bordes, cubiertos de un grueso manto de tobas, de las que todavía conservan restos, como capas no interrumpidas que van de los bordes más bajos hacia la mayor altura, indicando su posición la pendiente original del terreno.

No es nuestro deseo entrar aquí en explicaciones so 
bre la formación de los cráteres de explosión que hemos convenido en llamar Xalapazcos. Los cráteres de explosión se encuentran en regiones volcánicas, de larga historia de evolución; se supone que causas muy locales han favorecido ó determinado la manifestación volcánica, cuyo resultado final es la formación de un gran cráter, y por último, que la fuerza de la explosión se halla de tal manera localizada que es incapaz de engendrar movimientos ó rupturas en el terreno que se produce, de tal modo, que sólo se concentra en un tubo ó chimenea de pequeño diámetro. El cráter de explosión de Tacámbaro, como todos los de su especie, abrió un sacabocado en las rocas de la Corucha, sin dar lugar á movimiento alguno en las rocas, en las cuales se abrió la chimenea.

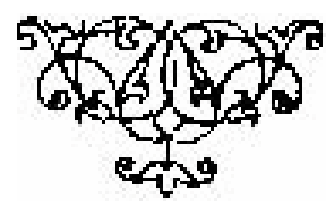

